\title{
nature
}

18/25 December 2003 Volume 426 Issue no 6968

\section{Secrecy damages the NIH}

An extensive piece of investigative journalism has highlighted conflicts of interest that cast a pall over the National Institutes of Health. The agency will lose its well-earned public trust if it does not radically increase its transparency.

A t first sight, it looked like the biggest misconduct scandal for years: scientists at the world's largest research campus riding the gravy train of lucrative private consulting deals that have distorted research and possibly even led to the deaths of patients in clinical trials. At least, that is how an extensive article in the Los Angeles Times on 7 December portrayed the situation at the US National Institutes of Health (NIH).

In response to the coverage, a congressional committee has demanded records of consulting arrangements at the NIH going back four years. Hearings seem likely. And NIH director Elias Zerhouni has promised a thorough review of consulting practices and ethics rules.

Although such responses are appropriate, the magnitude of the offences seems unlikely to be as worrying as the article implied which is probably why other media have not pounced on the story. What appears at first to be damning evidence of industry distortion of public medical research is actually rather inconclusive. The article details the consulting deals of a number of high-ranking NIH officials and describes how each posed an alleged conflict of interest. But it is also possible that each official was behaving within ethical bounds.

In one example, Stephen Katz, director of the National Institute of Arthritis and Musculoskeletal and Skin Diseases, was reportedly reluctant to halt a trial of an anti-inflammatory drug in the wake of a patient's death, while at the same time serving as a paid consultant to the maker of the drug. But Katz says he did not know that the drug was made by his client, because it was provided by a differently named
US affiliate. Furthermore, as with all the other consulting deals mentioned in the article, Katz's was subject to ethical review and approval.

Permitting employees to engage in private consulting is essential to the vitality of the NIH. By the mid-1990s, the agency was losing talent to industry and academia, where higher pay and private consulting are common. When Harold Varmus took the helm in 1993, he was charged with revitalizing research. By allowing researchers to increase their consulting income, he helped to turn the tide.

The NIH's policies on such matters are open to public scrutiny (see http://ethics.od.nih.gov), but the practice is not. Private consulting, which in the NIH must be done in "personal time", can open the way for conflicts of interest. Even assuming that proper safeguards are in place, one disturbing fact remains. Of the 2,259 current consulting deals made by NIH employees in the upper salary brackets, only 127 are subject to full public disclosure — a statistic that even Varmus says he finds disconcerting. The rest fall through an administrative loophole that permits many top-level researchers to file minimal details of their outside agreements, and then for internal use only.

As the pending congressional review demonstrates, the appearance of impropriety can be as damaging as impropriety itself. The only way forward is transparency. Public officials throughout government engage in private consulting, but that consulting must be open to public scrutiny. The public should not be asked to take the NIH's word that its staff are behaving well in such sensitive areas of responsibility. They should be able to see for themselves.

\section{Variation for all}

The consortium that is mapping human haplotypes establishes some important principles of access and credit in this issue.

W hat is the logical next step after completing the sequence of one human's genome? The international human genomics community thinks it is to catalogue the differences between humans, and to decode their importance to health and diseases. So researchers are building a map of common variation in the human genome, using combinations of markers that yield mosaic-like patterns called haplotypes (see Nature 421, 409-412; 2003).

The International HapMap Project (www.hapmap.org; short for haplotype mapping) is a large-scale public and private research collaboration that will use 270 human genomes from four populations to generate a publicly available tool for use by biomedical researchers anywhere (see Nature425, 758-759;2003). Given the project's pledge to ensure rapid and complete data release, a question arises about how those doing the work receive the credit for their contributions.

In January 2003, representatives of the publicly funded genomics community met in Fort Lauderdale, Florida, to address the tension between public access to large-scale data sets and proper credit for the researchers (see Nature 421, 875; 2003 and www.wellcome.ac.uk/ en/1/awtpubrepdat.html). A proposed solution was to define certain projects as 'community resource projects', where different rules apply for the distribution of data pre-publication and for publication. Examples include the recent publicly funded human and mouse genome-sequencing projects, and the International HapMap Project. For community-resource projects, the group suggested a new type of publication called a 'project description', the purpose of which is "to inform the scientific community about the resource project and to provide a citation to reference the source of the data".

We are pleased to publish, on page 789 of this issue, the project description for the International HapMap Project. Anyone who uses the HapMap data in their own publication - even before those who generated the primary data have published their analysis - can now properly cite the plans laid out by the originators. Another benefit is that the many scientists at all levels who are already contributing to an important project have something to show for it in their CVs.

In the paper, the International HapMap Consortium describes its strategy for dealing with patient consent and ascertaining samples, and the inherent conflict in making data available rapidly and freely while heading off possible patenting issues by imposing a 'click-wrap' agreement on individual genotypes. As with many large-scale projects, the process leading to the results is complex, and issues such as the best way to analyse the mountains of data remain to be resolved. Nature supports this publication of the planned way forward to generate discussion, to give credit where it's due, and to promote the idea that such openness is in the best interests of science. 